\title{
Nanostructured metal particle-modified electrodes for electrocatalytic and sensor applications
}

\author{
RAMASAMY RAMARAJ \\ Centre for Photoelectrochemistry, School of Chemistry, Madurai Kamaraj University, Madurai 625021 \\ e-mail: ramarajr@yahoo.com
}

\begin{abstract}
Nanotechnology has become one of the most exciting frontier fields in analytical chemistry. The huge interest in nanomaterials, for example in chemical sensors and catalysis, is driven by their many desirable properties. Although metal is a poor catalyst in bulk form, nanometre-sized particles can exhibit excellent catalytic activity due to their relative high surface area-to-volume ratio and their interface-dominated properties, which significantly differ from those of the bulk material. The integration of metal nanoparticles into thin film of permselective membrane is particularly important for various applications, for example in biological sensing and in electrocatalysis. We have already established different techniques to design permselective membrane-coated chemically modified electrodes with incorporated redox molecules for electrocatalytic, electrochromic and sensor applications. Recently, we have prepared nanostructured platinum and copper (represented $\mathrm{M}_{\text {nano }}, \mathrm{M}=\mathrm{Pt}$ and $\mathrm{Cu}$ ) modified $\mathrm{GC} / \mathrm{Nafion}$ electrodes $\left(\mathrm{GC} / \mathrm{Nf} / \mathrm{M}_{\text {nano }}\right)$ and characterized by using AFM, XPS, XRD and electrochemical techniques. The nanostructured $\mathrm{M}_{\text {nano }}$ modified electrodes were utilized for efficient electrocatalytic selective oxidation of neurotransmitter molecules in the presence of interfering species such as ascorbic acid (AA) and uric acid (UA). It has been also shown that the modified electrodes could be used as sensors for the detection of submicromolar concentrations of biomolecules with practical applications to real samples such as blood plasma and dopamine hydrochloride injection solution. The $\mathrm{GC} / \mathrm{Cu}_{\text {nano }}$ electrode has been used for catalytic reduction of oxygen.
\end{abstract}

Keywords. Metal nanoparticles; platinum; copper; Nafion ${ }^{\circledR}$; modified electrode; electrocatalysis; sensor.

\section{Introduction}

Nanoparticles-on-electrodes comprise a fundamentally interesting class of materials, in part because of an apparent dichotomy which exists between their sizes and many of their physical and chemical properties. ${ }^{1-5}$ In the electrodeposition of metal particles, the most common method involves the reduction of appropriate metal salts in the presence of stabilizers such as polymers, surfactants or special ligands which prevent undesired formation of insoluble bulk metal particles. Nanoparticles could facilitate electron transfer reactions and this coupled with an ease of miniaturization of sensing devices to nanoscale dimensions make nanoparticles suitable for important applications in chemical/biochemical sensing because of their high surface-to-volume ratio and highly effective catalytic properties. ${ }^{1-8}$ In particular, platinum (Pt) nanoparticles has been an intensive research subject for the design of nanostructured electrodes. The combination of the electronic conductivity and electroactivity of metal nanoparticles with high ionic conductivity and ion-exchange capacity of Nafion ${ }^{\circledR}$ (Nf) provides much scope for the design of nanoparticles on $\mathrm{Nf}$ film modified electrodes with novel properties and applications. ${ }^{9-13}$ Electrocatalytic reactions are of central importance in electrochemistry and play a vital role in emerging technologies related to environmental and energy-related applications. ${ }^{1-14} \mathrm{Pt}$-group nanoparticles in the size range of 2-10 $\mathrm{nm}$, employed commercially in fuel cells and related applications, exhibit various interesting electronic and coordinative properties. ${ }^{15}$

Oxygen reduction has been widely studied in both acidic and basic electrolyte solutions because of its fundamental importance in electrochemistry and also in fuel cell applications. ${ }^{16-20}$ On the other hand, its reduction in neutral solution is interesting in the development of biosensors for dissolved oxygen in biological processes. Metal microparticles deposited on electrode surfaces with and without polymer coatings and their resulting electrocatalytic properties have been reported. ${ }^{21,22}$ Polymer films, such as poly(4-vinylpyridine) and polypyrrole, enhance the 
stability and dispersity of the embedded Pt particles on GC electrodes. Use of deposited metal particles for both hydrogen evolution and oxygen reduction has been investigated. ${ }^{21-23}$

Dopamine (DA) is one of the most significant catecholamines and belongs to the family of excitatory chemical neurotransmitters. ${ }^{24-27}$ The important challenges to measure DA under physiological conditions utilizing electrochemical methods are: the very low concentration levels of DA (in the submicromolar range) and the intensive interference arising from the electroactive ascorbate (AA) that is present at relatively high concentrations $(0 \cdot 2-0.5 \mathrm{mM})$. These problems exist due to the very close oxidation potentials of DA and its metabolites and AA at the bare electrodes. Several reports have demonstrated that the films such as Nafion, ${ }^{28}$ clay, ${ }^{29}$ melanin polymer ${ }^{30}$ at physiological could attract and preconcentrate biomolecules such as cationic DA while effectively rejecting the anionic AA and other anionic interfering agents. This paper mainly presents some of our recent work ${ }^{31-35}$ on the applications of nanostructured $\mathrm{Pt}$ and $\mathrm{Cu}$ electrodeposited on plain and $\mathrm{Nf}$ film coated electrodes for the simultaneous detection and determination of biomolecules in the presence of interference molecules and the reduction of oxygen. These metal nanoparticle-modified electrodes, coupled with the permselective $\mathrm{Nf}$ membrane, promote the adsorption and electron-transfer reactions of substrate molecules.

\section{Electrochemical deposition of nanostructured platinum and copper on electrode}

Electrodeposition of nanostructured $\mathrm{Pt}$ on the $\mathrm{Nf}$ or clay (bentonite clay) film coated glassy carbon (GC) and indium tin oxide (ITO) electrodes were carried out by electrochemical methods. ${ }^{36} \mathrm{Nf}$ films were coated on GC and ITO electrodes by transferring known volume of $\mathrm{Nf}$ or clay solution on the electrode surface and allowing the solvent to evaporate at room temperature. Subsequently, the GC/Nf and GC/clay electrodes were kept in distilled water for 30 min. Thicknesses of the Nafion and clay films were calculated by knowing the density of $1.58 \mathrm{~g} / \mathrm{cm}^{3}$ for Nafion ${ }^{37}$ and $1.77 \mathrm{~g} / \mathrm{cm}^{3}$ for clay. ${ }^{38}$ The electrodes (GC, GC/Nf, GC/clay, ITO and ITO/Nf) were dipped in a mixture of deaerated $1 \mathrm{M} \mathrm{H}_{2} \mathrm{PtCl}_{6}$ and $1 \mathrm{M} \mathrm{HClO}_{4}$ solution for $5 \mathrm{~min}$ followed by continuous scanning of the electrodes between the potentials 1.0 and $-0.1 V(\mathrm{SCE})$ to deposit Pt particles onto the electrodes. The electrodes were washed and dipped in distilled water and used for electrochemical experiments (referred as $\mathrm{GC} / \mathrm{Pt}_{\text {nano }}, \mathrm{GC} / \mathrm{Nf} / \mathrm{Pt}_{\text {nano }}$, GC/clay/ $\mathrm{Pt}_{\text {nano }}, \mathrm{ITO} / \mathrm{Pt}_{\text {nano }}$ and $\left.\mathrm{ITO} / \mathrm{Nf} / \mathrm{Pt}_{\text {nano }}\right)$. These metal nanoparticle-modified electrodes were used for oxygen reduction and simultaneous detection and determination of biomolecules. Nanostructured copper particles were deposited electrochemically on GC and ITO electrodes $\left(\mathrm{GC} / \mathrm{Cu}_{\text {nano }}\right.$ and $\left.\mathrm{ITO} / \mathrm{Cu}_{\text {nano }}\right)$ using deaerated solutions of $0.01 \mathrm{M} \mathrm{CuSO}_{4}$ and $0.1 \mathrm{M}$ $\mathrm{NaClO}_{4}$ under different applied potentials $\left(E_{\text {app }}=0 \cdot 0\right.$ to $-0.6 \mathrm{~V}(\mathrm{SCE})$ ). Better electrocatalytic activity could be achieved when $\mathrm{Cu}_{\text {nano }}$ was electrodeposited at $-0.4 \mathrm{~V}$ at a charge of $700^{\circ} \mathrm{C}$.

\section{Characterization of $\mathbf{P t}_{\text {nano }}$ and $\mathrm{Cu}_{\text {nano }}$ modified electrodes}

The continuous cyclic voltammograms recorded between 1.0 and $-0.1 \mathrm{~V}$ at a scan rate of $10 \mathrm{mV} / \mathrm{s}$ for $\mathrm{GC}, \mathrm{GC} / \mathrm{Nf}$ and $\mathrm{GC} /$ clay electrodes dipped in $1 \mathrm{M}$ $\mathrm{H}_{2} \mathrm{PtCl}_{6}$ and $1 \mathrm{M} \mathrm{HClO}_{4}$ are shown in figure $1 .^{31,32} \mathrm{In}$

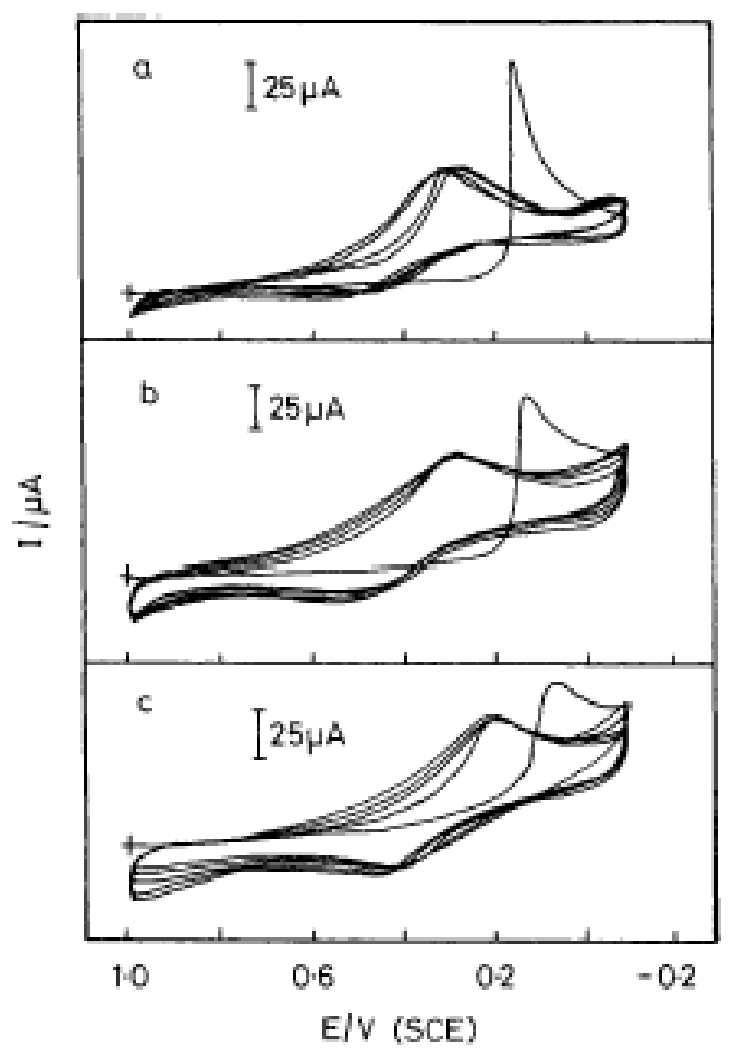

Figure 1. Continuous cyclic voltammograms of (a) GC, (b) $\mathrm{GC} / \mathrm{Nf}$ and (c) $\mathrm{GC} / \mathrm{BT}$ electrodes in deaerated $1 \mathrm{M}$ $\mathrm{H}_{2} \mathrm{PtCl}_{6}$ and $1 \mathrm{M} \mathrm{HClO}_{4}$. Scan rate $=10 \mathrm{mV} / \mathrm{s}$. 
the first scan the four-electron reduction of $\mathrm{Pt}(\mathrm{IV})$ to $\operatorname{Pt}(0)^{39}$ occurred at $0 \cdot 1 \mathrm{~V}$ (figure 1). ${ }^{31,32}$ In subsequent cycles, the peak current at $0 \cdot 1 \mathrm{~V}$ disappeared and a new irreversible reduction peak was observed at $0.3 \mathrm{~V}$. This indicates that the deposition of Pt particles occurred in the first cycle and $\mathrm{Pt}$ underwent oxidation at $>0.5 \mathrm{~V}$ in the oxidative scan. ${ }^{31,32}$

The electrochemical properties of nanostructured $\mathrm{Pt}$ were studied at different $\mathrm{pH}$ in the range $1-7$. The reduction peak potential of $\mathrm{Pt}$ was found to be dependent on the solution $\mathrm{pH}^{33,34}$ Figure 2 shows the $\mathrm{PtO}$ reduction peak potentials recorded for GC/Nf/ $\mathrm{Pt}_{\text {nano }}$ electrode at varying $\mathrm{pH}$. The irreversible reduction peak potential shifts to more negative potentials and the reduction peak potentials fit well to a straight line in the $\mathrm{pH}$ range 1.0 to 7.0 (figure 2), while the slope of the straight line is found to be $59 \mathrm{mV} / \mathrm{pH}$. The shift in the peak potential with respect to $\mathrm{pH}$ has been attributed to proton-coupled reaction, (1). The intercept value of $0.4 \mathrm{~V}$ (figure 2) confirms the reduction behaviour of the $\mathrm{Pt}_{\text {nano }}$ deposited on the GC/Nf electrode. ${ }^{33,34}$

$$
\mathrm{PtO}+2 \mathrm{e}^{-}+2 \mathrm{H}^{+} \rightarrow \mathrm{Pt}+\mathrm{H}_{2} \mathrm{O}
$$

The AFM image recorded for the ITO/Nf/ $/ t_{\text {nano }}$ electrode is shown in figure 3. The $\mathrm{Pt}_{\text {nano }}$ are homogeneously distributed on the electrode surface forming a densely packed film and each particle is in contact with adjacent ones. The electrodeposition of $\mathrm{Pt}_{\text {nano }}$

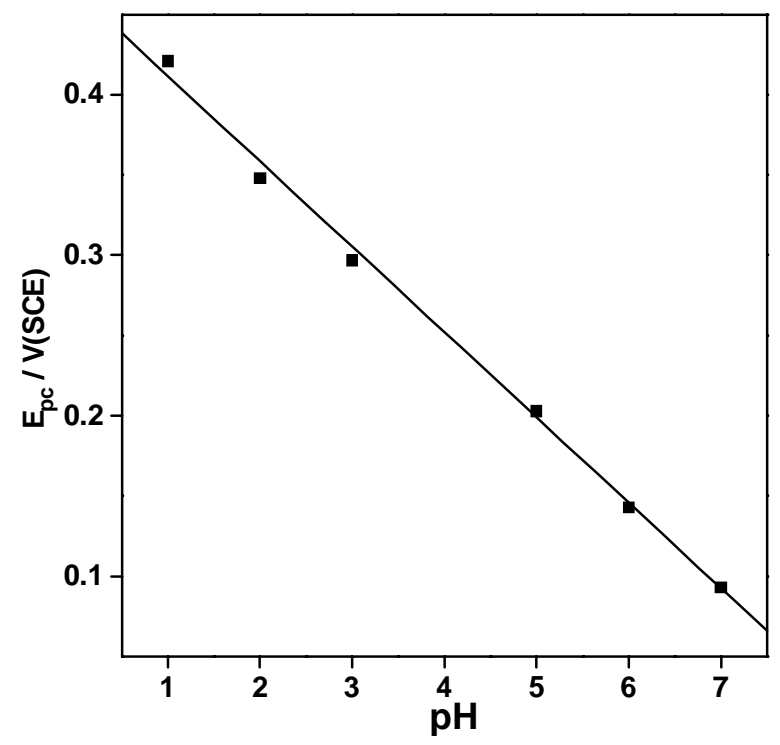

Figure 2. Plot of $\mathrm{pH}$ against the cathodic peak potential $\left(E_{\mathrm{pc}}\right)$ for $\mathrm{GC} / \mathrm{Nf} / \mathrm{Pt}_{\text {nano }}$ electrode. leads to the formation of nanostructured $\mathrm{Pt}_{\text {nano }}$ with smaller grains in the range $25-50 \mathrm{~nm}$ and larger aggregates of about $500 \mathrm{~nm}^{33,34} \mathrm{The} \mathrm{Pt}_{\text {nano }}$ deposited on the electrode was also characterized by X-ray photoelectron spectroscopy (figure 4) and X-ray diffraction studies. ${ }^{33,34}$

Figure 4 shows the XPS obtained for the $\mathrm{Pt}_{\text {nano }}$ deposited on the Nf film coated electrode. The peak with binding energy of $71.2 \mathrm{eV}$ is assigned to the presence of $\mathrm{Pt}^{40,41}$ The peak at $74.8 \mathrm{eV}$ is more difficult to assign because bulk $\mathrm{PtO}_{2}$ and $\mathrm{Pt}(\mathrm{OH})_{4}$ show similar binding energies ${ }^{40,41}(74.7$ and $74.3 \mathrm{eV}$, respectively).

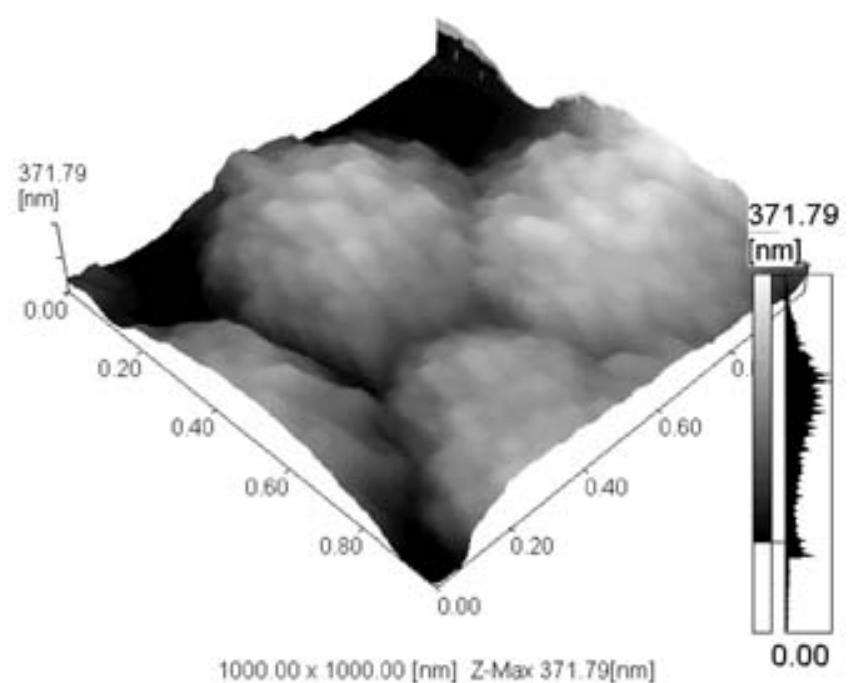

Figure 3. Tapping-mode 3D AFM image $(1 \mu \mathrm{m} \times$ $1 \mu \mathrm{m})$ of ITO/Nf/Pt ${ }_{\text {nano }}$ electrode surface.

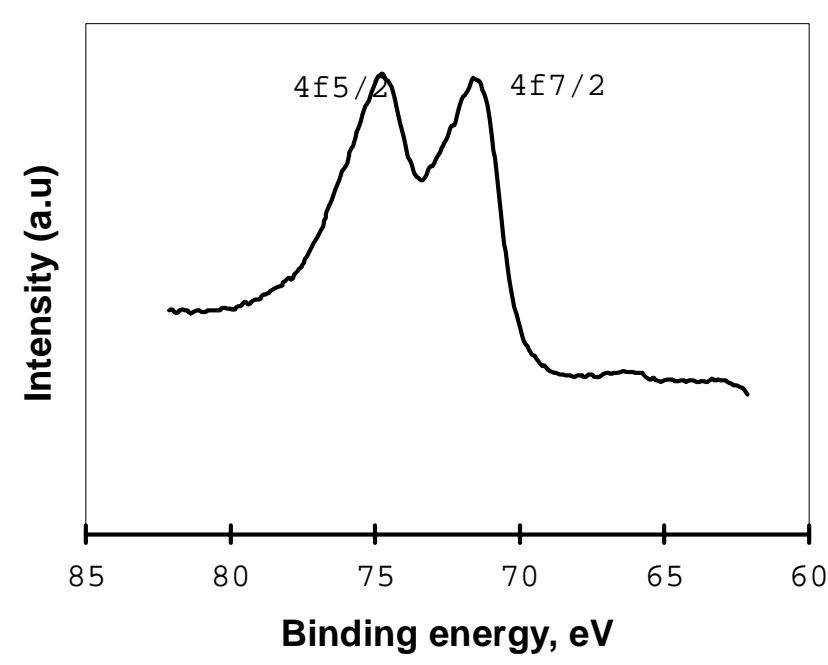

Figure 4. XPS of $\operatorname{Pt}\left(4 \mathrm{f}_{7 / 2-5 / 2}\right)$ core-level spectra of electrodeposited $\mathrm{Pt}_{\text {nano }}$ on the ITO/Nf electrode (ITO/Nf/ $\left.\mathrm{Pt}_{\text {nano }}\right)$. 
The AFM image of nanostructured $\mathrm{Cu}$ deposited $\mathrm{Nf}$ film-coated ITO electrode (ITO/ $\mathrm{Nf} / \mathrm{Cu}_{\text {nano }}$ ) is shown in figure 5 . The sizes of the aggregates measured from the cursor plot vary from 20 to $200 \mathrm{~nm}$. This observation shows that the electrodeposition of $\mathrm{Cu}_{\text {nano }}$ leads to the formation of nanostructured $\mathrm{Cu}$ particles with smaller grains in the range $15-25 \mathrm{~nm}$ and larger aggregates in the range 130-200 $\mathrm{nm}$. The $\mathrm{Cu}_{\text {nano }}$ formed on the electrode was also characterized by X-ray photoelectron spectroscopy and X-ray diffraction studies. ${ }^{34,35}$ The emission of $2 p$ photoelectrons from $\mathrm{Cu}$ is identified in two peaks of the XPS spectra, one is assigned to $\mathrm{Cu}(0)(935 \mathrm{eV})$ and the other one to $\mathrm{Cu}(\mathrm{I})(955 \mathrm{eV})$. The observed $\mathrm{Cu}(2 p)$ binding energies indicate the presence of $\mathrm{Cu}(0)$ and $\mathrm{Cu}(\mathrm{I})\left(\mathrm{Cu}_{2}{ }_{2} \mathrm{O}\right)$ species. $^{42}$

\section{Oxygen reduction at nanostructured Pt modified electrode}

Cyclic voltammograms recorded for GC/Pt, GC/Nf/ $\mathrm{Pt}_{\text {nano }}$ and $\mathrm{GC} / \mathrm{clay} / \mathrm{Pt}_{\text {nano }}$ electrodes dipped in oxygenated $0 \cdot 1 \mathrm{M} \mathrm{H}_{2} \mathrm{SO}_{4}$ showed an irreversible reduction peak at $0.4 \mathrm{~V}$ with increased cathodic peak current when compared to plain GC electrode. When the potential range was increased from 0.6 to $1.3 \mathrm{~V}$ while running the cyclic voltammograms an increase in the cathodic peak current was observed at $0.4 \mathrm{~V}$. This observation showed that the $\mathrm{PtO}$ formed at the $\mathrm{Pt}_{\text {nano }}$ deposited electrode was involved in the $\mathrm{O}_{2}$ reduction process. The partial reduction product was found to be hydrogen peroxide $\left(\mathrm{H}_{2} \mathrm{O}_{2}\right)$. This indicates that the $\mathrm{O}_{2}$ undergoes two-electron reduction to the $\mathrm{H}_{2} \mathrm{O}_{2}$ at

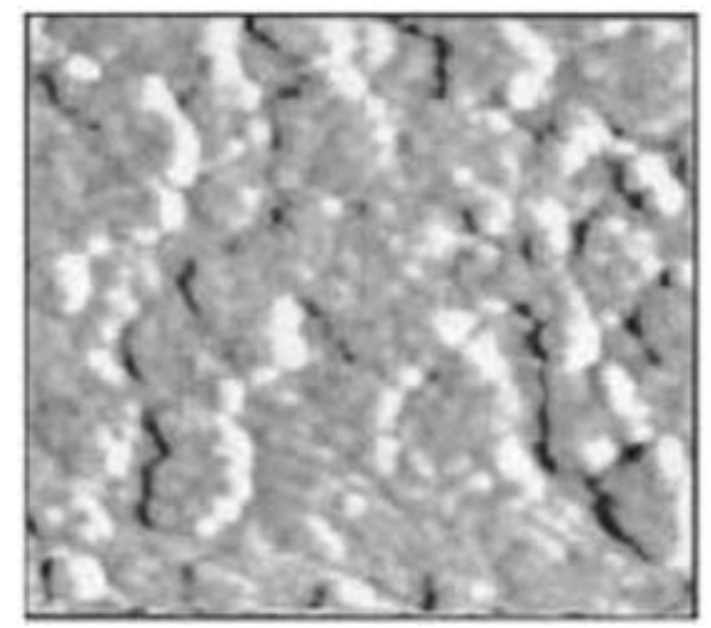

Figure 5. Tapping mode of $2 \mathrm{D}$ AFM image $(1.0 \mu \mathrm{m} \times$ $1.0 \mu \mathrm{m})$ of ITO/Nf/Cu $\mathrm{Cu}_{\text {nano }}$ electrode surface.
PtO-covered $\mathrm{Pt}_{\text {nano }}$ deposited electrode in addition to the four-electron reduction of $\mathrm{O}_{2}$ to water (figure 6). ${ }^{31,32}$

The $\mathrm{O}_{2}$ reduction reaction on $\mathrm{Pt}_{\text {nano }}$ proceeded through a pathway involving the adsorption of $\mathrm{O}-\mathrm{O}$ and decomposition of $\mathrm{O}-\mathrm{O}$ bond. ${ }^{43}$ In our work ${ }^{31,32}$ the PtO covered $\mathrm{Pt}_{\text {nano }}$ electrode favoured the partial desorption of the two-electron reduction product $\mathrm{H}_{2} \mathrm{O}_{2}$ into the solution. The adsorbed $\mathrm{H}_{2} \mathrm{O}_{2}$ was much more readily desorbed from the site on $\mathrm{PtO}$ than from the adsorption site involved in the fourelectron reduction process at $\mathrm{Pt}_{\text {nano }}$ (figure 7).

The amounts of $\mathrm{H}_{2} \mathrm{O}_{2}$ were measured at an applied potential of $0.4 \mathrm{~V}$ using the $\mathrm{Pt}_{\text {nano }}$ modified electrodes at different time intervals and the results are shown in figure $8 .^{31,32}$ At an applied potential of $0.4 \mathrm{~V}$ (using the anodized $\mathrm{GC} / \mathrm{Pt}_{\text {nano }}, \mathrm{GC} / \mathrm{Nf} / \mathrm{Pt}_{\text {nano }}$ and $\mathrm{GC} / \mathrm{clay} / \mathrm{Pt}_{\text {nano }}$ electrodes at $\left.>1.0 \mathrm{~V}\right)$, the amounts of $\mathrm{H}_{2} \mathrm{O}_{2}$ were observed as 0.0, 0.031, 0.053 and $0.045 \mu$ moles in $30 \mathrm{~min}$, respectively. The analysis of the charge accumulated at the $\mathrm{O}_{2}$ reduction potential $(0.4 \mathrm{~V})$ showed that $\sim 40 \%$ of the conversion of $\mathrm{O}_{2}$ to $\mathrm{H}_{2} \mathrm{O}_{2}$ occurred at the $\mathrm{PtO}$ covered $\mathrm{Pt}_{\text {nano }}$ deposited electrodes. At $30 \mathrm{~min}$, the $\mathrm{PtO}$ might undergo reduction to $\mathrm{Pt}_{\text {nano }}$ at $0.4 \mathrm{~V}$ in addition to the $\mathrm{PtO}$

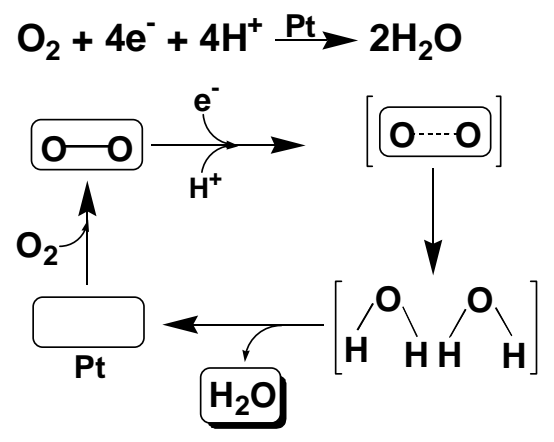

$\mathrm{O}_{2}$ adsorption and $\mathrm{O}-\mathrm{O}$ bond decompsoition on $\mathrm{Pt}$.

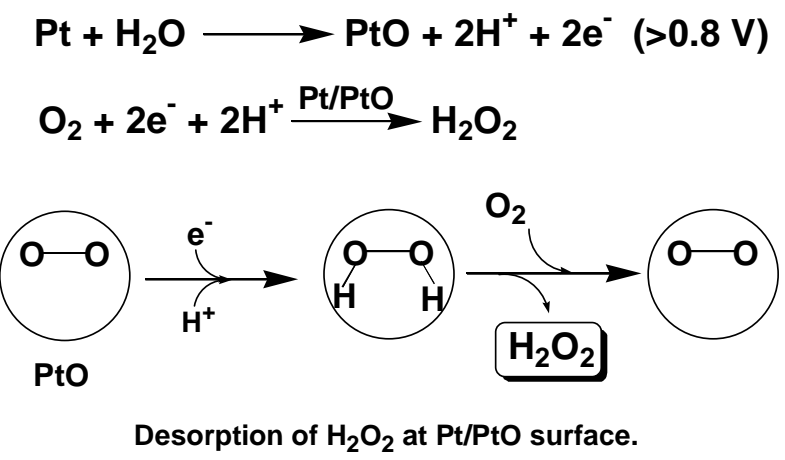

Figure 6. Schematic representation of $\mathrm{O}_{2}$ reduction reactions at $\mathrm{Pt}_{\text {nano }}$ and $\mathrm{Pt}_{\text {nano }} / \mathrm{PtO}$ modified electrode. 
catalysed $\mathrm{O}_{2}$ reduction and the amount of formation of $\mathrm{H}_{2} \mathrm{O}_{2}$ reached a maximum. When $\mathrm{Pt}_{\text {nano }}$ at the modified electrodes was again anodized, $\mathrm{PtO}$ catalysed reduction of $\mathrm{O}_{2}$ to $\mathrm{H}_{2} \mathrm{O}_{2}$ was observed. ${ }^{31,32}$

\section{Simultaneous detection of biomolecules at nanostructured Pt modified electrode}

Figure 9 shows the anodic DPV responses of $100 \mu \mathrm{m}$ $\mathrm{DA}$ at the plain $\mathrm{GC}, \mathrm{GC} / \mathrm{Pt}_{\text {nano }}$ and $\mathrm{GC} / \mathrm{Nf} / \mathrm{Pt}_{\text {nano }}$ electrodes in phosphate buffer ( $\mathrm{pH} 7 \cdot 2)$. The oxidation of DA appeared at $0 \cdot 13 \mathrm{~V}$ at $\mathrm{GC} / \mathrm{Nf} / \mathrm{Pt}_{\text {nano }}$ electrode. A shift of about $60 \mathrm{mV}$ to more negative

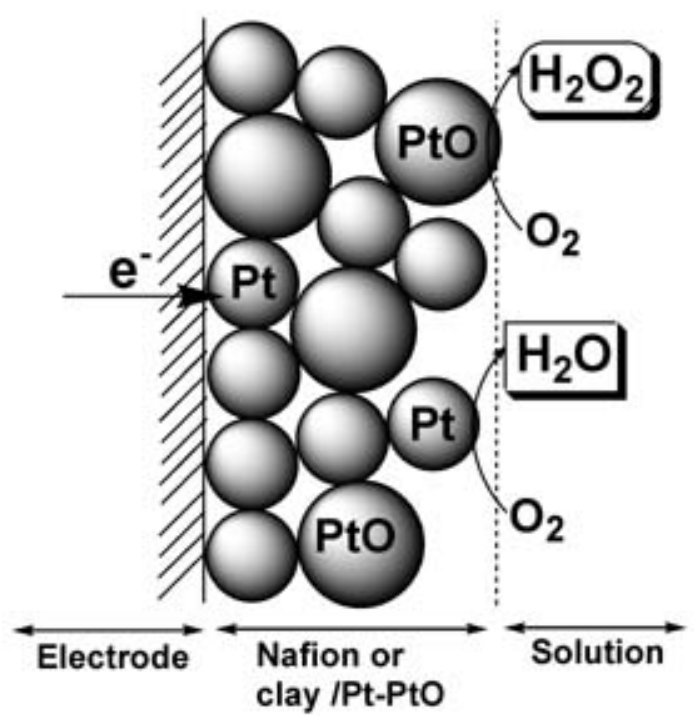

Figure 7. Schematic representation of $\mathrm{O}_{2}$ reduction to $\mathrm{H}_{2} \mathrm{O}$ and $\mathrm{H}_{2} \mathrm{O}_{2}$ at $\mathrm{PtO}$ covered $\mathrm{Pt}_{\text {nano }}$ deposited GC electrode. (Before $\mathrm{O}_{2}$ reduction experiment, the $\mathrm{Pt}_{\text {nano }}$ modified electrode was oxidized at $>0.8 \mathrm{~V}$.)

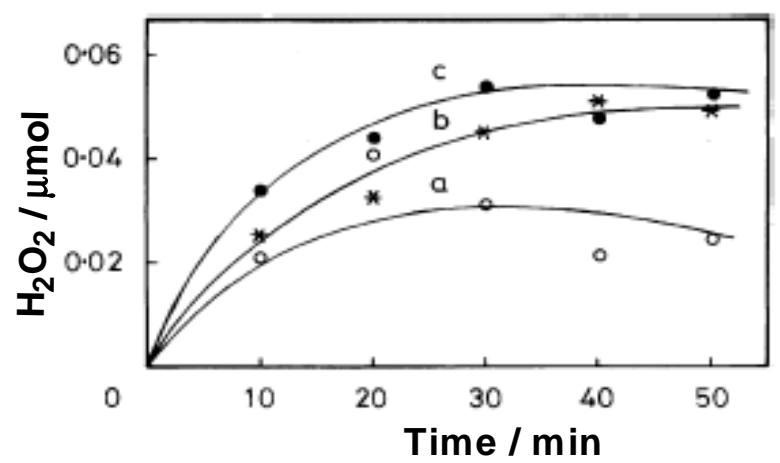

Figure 8. Amounts of $\mathrm{H}_{2} \mathrm{O}_{2}$ formed at the anodized $\mathrm{GC} / \mathrm{Pt}_{\text {nano }}$ (a), GC/Nf/Pt nano (b) and $\mathrm{GC} / \mathrm{clay} / \mathrm{Pt}_{\text {nano }}$ (c) electrodes at an applied potential of $0.4 \mathrm{~V}$ dipped in oxygenated $0 \cdot 1 \mathrm{M} \mathrm{H}_{2} \mathrm{SO}_{4}$. potential for $\mathrm{DA}$ was observed at $\mathrm{GC} / \mathrm{Nf} / \mathrm{Pt}_{\text {nano }}$ when compared to plain GC electrode with an 11.6 fold enhancement of peak current (figures $9 \mathrm{a}$ and c). The electrochemical deposition of $\mathrm{Pt}_{\text {nano }}$ on $\mathrm{Nf}$ film-coated electrode $\left(\mathrm{GC} / \mathrm{Nf} / \mathrm{Pt}_{\text {nano }}\right)$ (figures $9 \mathrm{~b}$ and $\mathrm{c}$ ) increases the anodic peak current of DA when compared to the $\mathrm{GC} / \mathrm{Pt}_{\text {nano }}$ electrode. The voltametric experiments were also carried out using the $\mathrm{GC} / \mathrm{Nf} / \mathrm{Pt}_{\text {nano }}$ electrode with different concentrations of DA and the peak current was found to be proportional to the concentration of dopamine in the range from $3 \times 10^{-6}$ $60 \times 10^{-6} \mathrm{M}$ DA with a detection limit of $10 \mathrm{nM} \cdot .^{33,34}$

Ascorbic acid (AA) and uric acid (UA) are the important interference molecules in the measure-

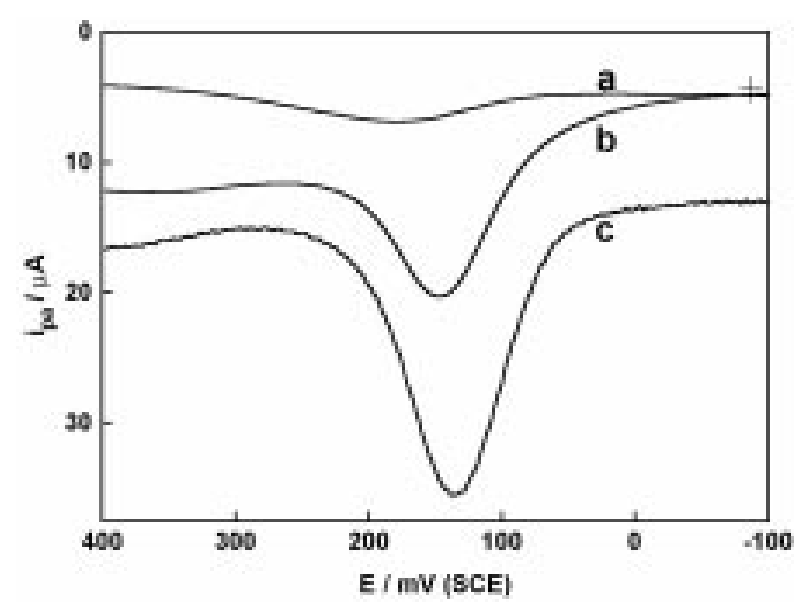

Figure 9. Anodic DPVs recorded for $100 \mu \mathrm{M}$ DA at plain $\mathrm{GC}(\mathrm{a}), \mathrm{GC} / \mathrm{Pt}_{\text {nano }}$ (b) and $\mathrm{GC} / \mathrm{Nf} / \mathrm{Pt}_{\text {nano }}$ (c) electrodes in $0 \cdot 1 \mathrm{M}$ phosphate buffer $(\mathrm{pH} \mathrm{7 \cdot 2)}$.

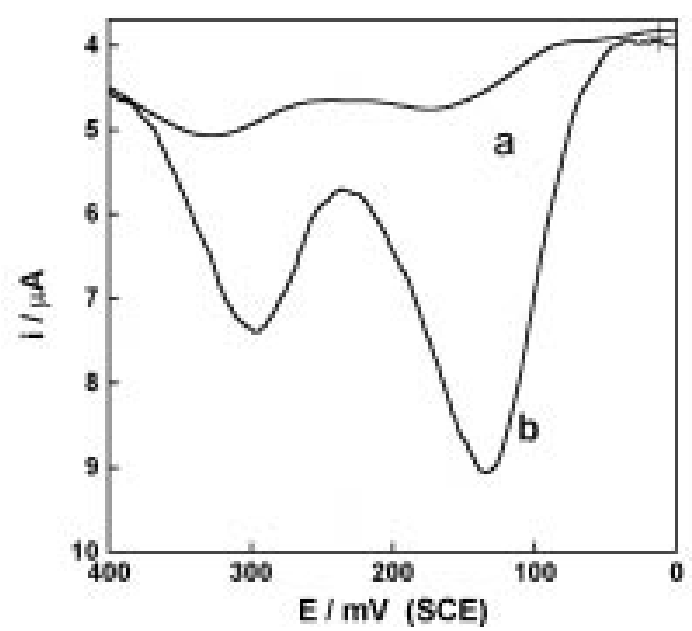

Figure 10. Anodic DPVs recorded at GC/Nf (a) and at $\mathrm{GC} / \mathrm{Nf} / \mathrm{Pt}_{\text {nano }}$ electrode (b) in $0 \cdot 1 \mathrm{M}$ PBS for a mixture of $50 \mu \mathrm{M}$ DA and $500 \mu \mathrm{M} 5-\mathrm{HT}$ in presence of $1.0 \mathrm{mM} \mathrm{AA}$ and $0 \cdot 1 \mathrm{mM}$ UA. 
ment of DA in biological systems and the oxidation potential of AA and UA are very close to that of DA. It has been demonstrated that Nf film is a sufficient barrier for several anionic interfering analytes and acts as a permselective membrane. ${ }^{24}$ Figure 10a clearly shows that the GC/Nf electrode is very effective in rejecting anions such as AA and UA and better peak separation for the mixture of DA and serotonin (5-HT) was also observed in the presence of higher concentrations of interferences such as AA and UA where the bare GC electrode could not distinguish between the four species and all four species showed a single peak at the same potential for a mixture of $50 \mu \mathrm{M} \mathrm{DA}, 500 \mu \mathrm{M} 5-\mathrm{HT}, 1 \mathrm{mM}$ AA and $0 \cdot 1 \mathrm{mM}$ UA (figure not shown). ${ }^{33,34}$

Figure $10 \mathrm{~b}$ shows the DPVs recorded for a mixture of DA and 5-HT at the GC/Nf/ $/ \mathrm{Pt}_{\text {nano }}$ electrode in the presence of AA and UA. The voltametric response

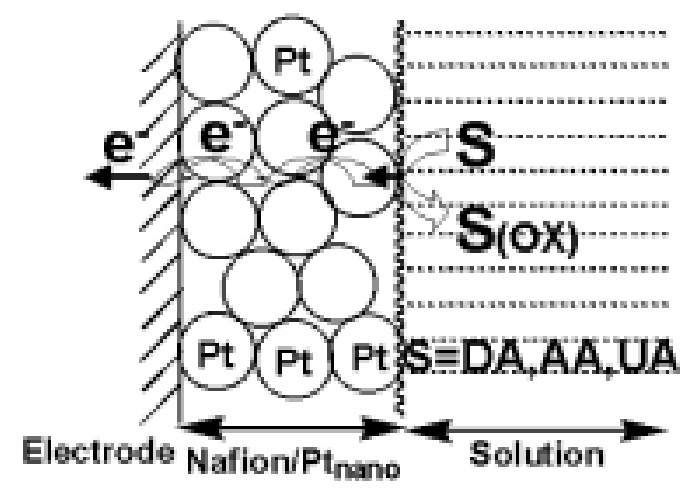

Figure 11. Schematic representation of oxidation of DA at the $\mathrm{GC} / \mathrm{Nf} / \mathrm{Pt}_{\text {nano }}$ electrode in the presence of interfering molecules such as AA and UA.

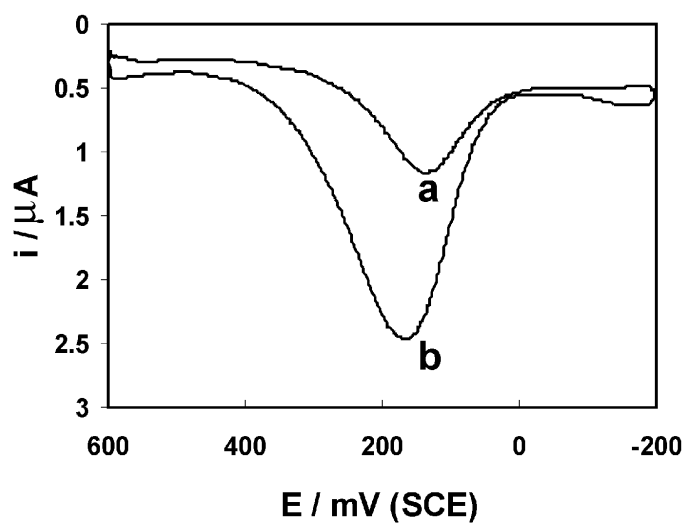

Figure 12. DPVs recorded at $\mathrm{GC} / \mathrm{Nf} / \mathrm{Pt}_{\text {nano }}$ for blood plasma sample (a), spike addition of $10 \mu \mathrm{M}$ DA (b) in $0 \cdot 1 \mathrm{M}$ phosphate buffer. observed for the mixture at the $\mathrm{GC} / \mathrm{Nf} / \mathrm{Pt}_{\text {nano }}$ electrode is dramatically increased and a large increase in the anodic peak current is observed when compared to $\mathrm{GC} / \mathrm{Nf}$ electrode (figure 10a). ${ }^{33,34}$

Figure 11 shows the schematic representation of selective electrocatalytic oxidation of cationic DA at the $\mathrm{GC} / \mathrm{Nf} / \mathrm{Pt}_{\text {nano }}$ electrode in the presence of anionic molecules such as A and UA. Figure 11 also explains the electron-mediating properties of $\mathrm{Pt}_{\text {nano }}$ towards the oxidation of DA in the presence of interferences such as AA and UA.

The application of $\mathrm{GC} / \mathrm{Nf} / \mathrm{Pt}_{\text {nano }}$ electrode for the detection and determination of DA in practical samples such as dopamine injection solution (DHI) and blood plasma was tested. ${ }^{34}$ Under the optimum conditions, the DPV peak currents were linearly related to DA concentration over the range from $1.0 \times 10^{-8}$ to $1.4 \times 10^{-6} \mathrm{M}$. A detection limit of $8 \mathrm{nM}$ was estimated at a signal-to-noise ratio of $\mathbf{3}$. DA was repeatedly determined in DHI samples with duplicate samples and the relative standard deviation was found to be $4.5 \%$. Interference studies were carried out with species such as AA and UA. Figure 12 shows the DPVs recorded using the GC/Nf/Pt $\mathrm{Pt}_{\text {nano }}$ electrode for blood plasma samples and spike addition of $10 \mu \mathrm{M}$ DA in blood plasma in $0.1 \mathrm{M}$ phosphate buffer. The recovery of DA and its metabolites in blood plasma (figure 12a) were calculated by spike addition with varying amounts of DA (figure 12b). Reproducibility of results was checked with three determinations.

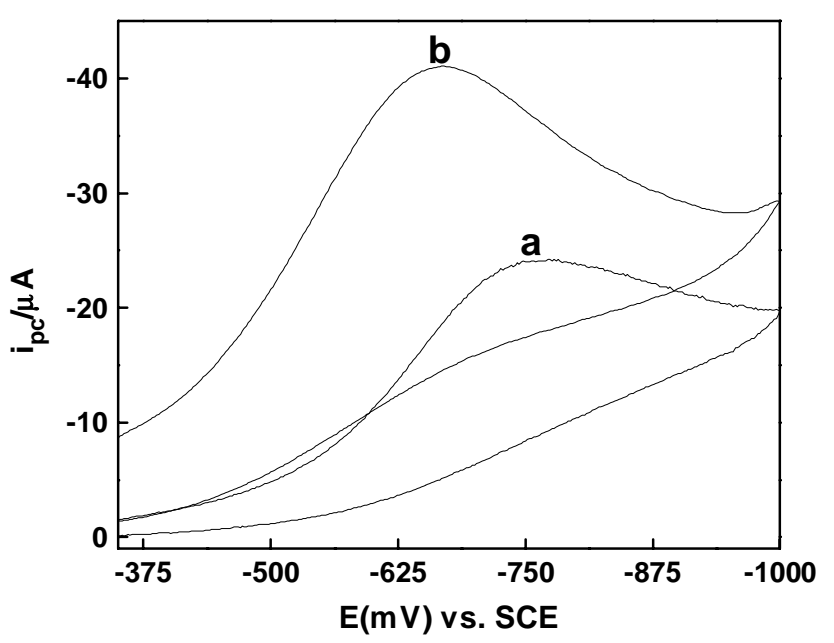

Figure 13. Cyclic voltammograms recorded at plain GC (a) and $\mathrm{GC} / \mathrm{Nf} / \mathrm{Cu}_{\text {nano }}$ (b) electrodes in $\mathrm{O}_{2}$ saturated $0 \cdot 1 \mathrm{M}$ PBS. $\mathrm{Cu}_{\text {nano }}$ was deposited at an applied potential of $0 \cdot 4 \mathrm{~V}(\mathrm{SCE})$. 


\section{Oxygen reduction at nanostructured $\mathrm{Cu}$ modified electrode}

Figure 13 shows the cyclic voltammograms recorded for $\mathrm{O}_{2}$ reduction at plain $\mathrm{GC}$ electrode (figure 13a) and after $\mathrm{Cu}_{\text {nano }}$ is incorporated into $\mathrm{Nf}$ film-coated GC electrode (figure 13b) in $\mathrm{O}_{2}$ saturated $0.1 \mathrm{M}$ PBS. $^{34,35}$ Under deaerated condition, the GC electrode did not show any reduction peak in the potential region -1.0 to $-0.35 \mathrm{~V}$. When the solution was saturated with oxygen, a reduction peak was observed in the voltammogram (figure 13). The $\mathrm{O}_{2}$ reduction peak was observed at $-0.76 \mathrm{~V}$ at plain $\mathrm{GC}$ electrode in $0.1 \mathrm{M}$ PBS. At GC/Nf/Cu nano electrode $\mathrm{O}_{2}$ reduction occurs at $-0.63 \mathrm{~V}$ with an increase in the reduction peak current and a decrease in overpotential when compared to plain GC electrode. This result suggests that the $\mathrm{GC} / \mathrm{Nf} / \mathrm{Cu}_{\text {nano }}$ electrode could be used for catalytic $\mathrm{O}_{2}$ reduction in neutral solution. It is reasonable to conclude that the major contribution to the peak current comes from the catalytic $\mathrm{O}_{2}$ reduction at $\mathrm{GC} / \mathrm{Nf} / \mathrm{Cu}_{\text {nano }}$ electrode. $\mathrm{Cu}_{\text {nano }}$ deposited at $-0.4 \mathrm{~V}$ on the modified electrode leads to the formation of multilayer copper nanostructures on the electrode surface. The $\mathrm{Cu}_{\text {nano }}$ modified electrode prepared at $-0.4 \mathrm{~V}$ showed better electrocatalytic behavior towards $\mathrm{O}_{2}$ reduction. ${ }^{34,35}$

In our laboratory, further work is in progress to design metal nanoparticles modified electrodes coupled with permselective membranes for the simultaneous detection and determination of biomolecules and for the electrocatalytic reduction of $\mathrm{O}_{2}$ and $\mathrm{H}_{2} \mathrm{O}_{2}$.

\section{Acknowledgements}

Financial support from the Department of Science and Technology (DST) and Council of Scientific and Industrial Research (CSIR), New Delhi is gratefully acknowledged.

\section{References}

1. Fendler J H (ed.) 1998 Nanoparticles and nanostructured films (Weinheim: Wiley-VCH)

2. Wieckowski A, Savinova E R and Vayenas C G (eds) 2003 Catalysis and electrocatalysis at nanoparticle surfaces (New York: Marcel Dekker)

3. Trasatti S 1994 in Electrochemistry of novel materials (eds) J Lipkowski and P N Ross (New York: VCH) Ch. 5
4. Zhou B, Hermans S and Somerjai G A (eds) 2004 In Nanotechnology in catalysis (London: Kluwer Academic/Plenum) vol. $1 \& 2$

5. Welch C M and Compton R G 2006 Anal. Bioanal. Chem. 384601

6. Hrapovic S, Liu Y, Male E B and Luong J H T 2004 Anal. Chem. 761083

7. Karyakin A A, Puganova E A, Budashov I A, Kurochkin I N, Karyakina E E, Levchenko V A, Matveyenko V N and Varfolomeyev S D 2000 Anal. Chem. 76474

8. D'Souza L and Sampath S 2000 Langmuir 168510

9. Mauritz K A and Moore R B 2004 Chem. Rev. 104 4535

10. Sirk A H C, Hill J M, Kung S K Y and Birss V I 2004 J. Phys. Chem. B108 689

11. Tan S, Laforgue A and Belanger D 2003 Langmuir 19744

12. Jia N, Lefcbvre M C, Halfyard J, Qi Z and Pickup P G 2000 Electrochem. Solid State Lett. 3529

13. Martin C R 1994 Science 2661961

14. Yin Y, Shen Y and Dong S 2004 J. Phys. Chem. B108 8142

15. Tong Y, Rice C, Wieckowski A and Oldfield E 2000 J. Am. Chem. Soc. 1221123

16. Collman J P, Denisevich P, Konai Y, Marrocco M, Koval C and Anson F C $1980 \mathrm{~J}$. Am. Chem. Soc. 102 6027

17. Sawyer D T 1991 Oxygen chemistry (New York: Oxford University Press)

18. Kinoshita K 1992 Electrochemical oxygen technology (New York: Wiley)

19. Srinivasan S and Bockris J O M 1969 Fuel cells: their electrochemistry (New York: McGraw-Hill)

20. Shukla A K and Raman R K 2003 Annu. Rev. Mater. Res. 33155

21. Rubinstein I and Bard A J $1980 \mathrm{~J}$. Am. Chem. Soc. 1026641

22. Bose C S C and Rajeshwar K 1992 J. Electroanal. Chem. 333235

23. Kost K M, Bartak D E, Kazee B and Kuwana T 1990 Anal. Chem. 62151

24. Gonon F, Buda M, Cespuglio R, Jouret M and Pujol J-F 1980 Nature (London) 286902

25. Wightman R M, May L J and Michael A C 1988 Anal. Chem. $60760 \mathrm{~A}$

26. Adams R N 1976 Anal. Chem. 48 1128A

27. Sternson A W, Mccreery R, Feinberg B and Adams R N 1973 J. Electroanal. Chem. 46313

28. Gerhardt G A, Oke A F, Rice M E and Adams R N 1984 Brain Res. 290390

29. Zen J-M and Chen P-J 1997 Anal. Chem. 695087

30. Rubianes M D and Rivas G A 2001 Anal. Chim. Acta 44099

31. Premkumar J and Ramaraj R 1997 J. Solid State Electrochem. 1172

32. Premkumar J 1997 Ph D thesis, Madurai Kamaraj University, Madurai

33. Selvaraju T and Ramaraj R 2005 J. Electroanal. Chem. $\mathbf{5 8 5} 290$ 
34. Selvaraju T 2005 Ph D thesis, Madurai Kamaraj University, Madurai

35. Selvaraju T and Ramaraj R 2005 Pramana-J. Phys. 65713

36. Jiang J and Kucernak A 2004 J. Electroanal. Chem. 567123

37. Martin C R, Rubinstein I and Bard A J 1982 J. Am. Chem. Soc. 1044817

38. Grim R E 1969 Clay mineralogy (New York: McGraw-Hill)
39. Dong S and Qiu Q 1991 J. Electroanal. Chem. 314 223

40. Wagner D 1990 in Practical surface analysis 2nd edn (eds) D Briggs and M P Scah (Chichester: Wiley) vol 1 , appendix 5

41. Bard A J and Faulkner L R 2001 Electrochemical methods, fundamentals and applications (New York: Wiley)

42. Sarkar D K, Zhou X J, Tannous A and Leung K T 2003 J. Phys. Chem. B107 2879

43. Yeager E 1984 Electrochim. Acta 291527 